\title{
Mediação narrativa na geração de 30: Graciliano Ramos e o empilhamento palimpséstico de vozes e recursos estilísticos
}

\author{
Marcelo Marinho* \\ Larissa Paula Tirloni**
}

\begin{abstract}
Resumo
Vidas secas (1938), de Graciliano Ramos, abraça as premissas do Romance de 30 e toma como pretexto o drama social e existencial dos retirantes para, por meio de expressivos recursos estilísticos transculturados de sua matriz poética europeia, induzir o leitor a uma prospecção no espaço existente entre a consciência (fictícia) dos personagens e o extenso e corrediço hipertexto em que se verbaliza o drama da própria condição humana. Em tal contexto, o objetivo do presente estudo é o de analisar as técnicas de escrita em Vidas secas, sobretudo no que se refere ao Discurso Indireto Livre, no intento de desnudar traços poéticos e estilísticos que permitem exprimir formas de mediação narrativa e induzem inúmeras possibilidades interpretativas. Por intermédio de um discurso que se desenvolve sob múltiplos registros de linguagem, o narrador apresenta-se como mediador de imbricadas cartografias da existência: os distintos focos narrativos e fontes de enunciação resultam de um exímio empilhamento palimpséstico de vozes de múltiplas origens.
\end{abstract}

Palavras-chave: Vidas secas. Condição humana. Geração de 30. Recursos estilísticos. Mediação discursiva.

O importante é escrever duas páginas no condicional sem que ninguém perceba.

(Graciliano Ramos, em declaração a Ricardo Ramos, 1987, p. 13).

* Universidade Federal da Integração Latino-Americana / Université de la Sorbonne Nouvelle. Licenciado, Mestre e Doutor em Literatura Comparada pela Université de la Sorbonne Nouvelle, é professor de Literatura Latino-Americana Comparada da UNILA.

** Universidade Federal da Integração Latino-Americana / Universidade Federal do Paraná. Professora de Língua Espanhola e Língua Portuguesa Adicional na Universidade Federal da Integração LatinoAmericana. Doutoranda em Estudos Literários pela Universidade Federal do Paraná. 


\section{Considerações iniciais}

$\mathrm{Na}$ aparente aridez poética que por vezes assola parte dos estudos críticos sobre a Geração de 30, um turbilhão de águas revoltas já se verteu para a identificação dos trechos em Discurso Indireto Livre (DIL) que se lançam nos costados dessa ilha literária cujo nome é Vidas secas [1938] (1979). Tais descrições se plasmam num dilúvio classificatório que, no mais das vezes, parte do pressuposto de que tal recurso expressivo resulta em mero jogo lúdico entre narrador e personagens (em que pese a natureza ficcional dessas entidades poéticas!). O presente estudo busca analisar, nesse texto inclassificável da literatura brasileira, a apropriação antropofágica e as técnicas transculturadas de mediação com a ferramenta poética do DIL, para além das formas canônicas anteriormente empregadas por Machado de Assis, Gustave Flaubert, Édouard Dujardin, James Joyce e Virginia Woolf, entre outros. Por tal viés, a análise busca cernir traços estilísticos de Graciliano Ramos que antecipam, em várias décadas, certas técnicas fílmicas (câmara subjetiva, analepses, prolepses) que vão marcar, por exemplo, Lavoura arcaica (2001), adaptação cinematográfica proposta por Luiz Fernando Carvalho para o romance homônimo de Raduan Nassar, filme que se revela como um divisor das águas no cinema contemporâneo.

Como pretexto poético para uma sondagem prospectiva dos abismos da alma, Vidas secas parte dos pressupostos temáticos do romance de 30 e traz à cena a deambulação randômica de uma família de retirantes nordestinos que tenta escapar da seca, da fome e das injustiças que brutalizam a existência dos seres humanos. A vida que se arrasta sobre o cáustico pó de gretas ressequidas reflete-se nas relações que bestializam os protagonistas Fabiano e Sinhá Vitória, assim como seus dois filhos (simbolicamente privados de nome), enquanto a célebre cachorra Baleia, em seu processo de antropomorfização, designa-se com um nome que talvez faça dela o mais humano entre os cinco protagonistas. No que se refere ao alcance expressivo do romance, Luís Bueno (2008, p. 75-76) discorre sobre as leituras propostas por Antonio Candido (1992) e afirma que, em Vidas secas, o crítico busca "as conexões internas da obra entre o que fora conseguido nos romances e o que se leva a cabo nas memórias". Por tal viés, Bueno conclui que "a obra de Graciliano Ramos elabora um arco que, partindo de uma observação do mundo, chega ao escrínio milimétrico do eu". 
No presente estudo, com base na ideia de prospecção dos abismos da alma humana que se espelha nas articulações entre narrador, personagens e leitor, analisaremos as antropofágicas técnicas de escrita de Graciliano Ramos e o alcance expressivo de seu romance, segundo três momentos hermenêuticos: na primeira parte abordaremos as relações de transgressão entre Vidas secas e a Geração de 30; a segunda parte se dedica ao trato de algumas características do Discurso Indireto Livre; por fim, a terceira parte reserva-se ao estudo das técnicas poéticas utilizadas em Vidas secas, no que se refere à mediação indutiva que se observa na relação entre o narrador, o leitor e o universo interior dos personagens.

\section{0 narrador em Vidas secas: sobre pretextos temáticos e transgressões poéticas}

Em inspirada asserção sobre as relações entre o mundo imaginário da literatura e o universo empírico, Michel Foucault afirma que o célebre personagem Dom Quixote monta em seu cavalo e lê o mundo para confirmar suas leituras de romances. Infere-se, por esse viés, que o narrador é um fundamental mediador entre leitor e personagens, entre universo fictício e universo cotidiano. Nesse contexto, Yves Reuter (1996) é um dos teóricos que, com esteio nas categorias literárias propostas por Gérard Genette, busca elucidar as funções do narrador de um texto literário. Tais funções podem se estruturar em cinco vertentes: a "comunicativa", que se manifesta quando o narrador se dirige diretamente ao narratário; a "metanarrativa", quando o narrador tece comentários sobre a organização da própria narrativa na qual se insere; a "testemunhal", que se expressa na relação pseudo-objetiva entre narrador e fatos narrados; a "explicativa", que implica a participação do narrador quanto à informação, ao narratário, de fatos relevantes para a compreensão do enredo; e a "generalizante", também qualificada como "ideológica", que reflete julgamentos e opiniões pessoais do narrador a respeito dos elementos inter e extra textuais da narração.

Ao longo do tempo, diferentes formas de mediação manifestam-se na obra de distintos autores e literaturas nacionais. Por exemplo, no século XIX, Machado de Assis, Gustave Flaubert e Édouard Dujardin aprimoram a técnica do Discurso Indireto Livre, anteriormente empregada em certos textos da literatura medieval e renascentista, segundo indicam os estudos de Bernard Cerquiglini (1984). Essa modalidade expressiva parte de um ponto de vista onisciente e onipresente para lançar o leitor no espaço em que se manifesta a própria dúvida: a consciência 
(fictícia) dos personagens. O narrador estabelece um diálogo imaginário com o leitor, sonegando informações e apresentando a versão parcial dos fatos, cabendo ao narratário abraçar a dúvida e a indecidibilidade próprias da existência humana, trazendo ao texto ficcional a possibilidade de multiplicar as vozes que se articulam por intermédio do narrador.

Por esse viés expressivo, cria-se um simulacro de impessoalidade para um narrador que se quer unicamente mediador das diferentes vozes emergentes no desenrolar da trama, como bem analisa Pierre Chartier (1995). Essa impessoalidade decorre da presença de um narrador mediador que se instaura no entrelugar corrediço e ambíguo em que se articulam o pensar e o falar de personagens, do autor, do leitor e dos múltiplos discursos virtuais que pertencem ao conjunto de textos (verbais ou não verbais) já produzidos pela humanidade. A leitura pressupõe a decodificação e o desmembramento concomitantes das diversas vozes que se empilham no discurso palimpséstico do narrador e das personagens, em enunciados que amalgamam suas próprias falas e introjetam falas alheias.

Em Vidas secas, as vozes mergulham na interioridade das personagens para fazer emergir um "mundo possível” por intermédio da representação de um universo fragmentado, distorcido, dissolvido em emoções e sensações inenarráveis. Caberia aqui mencionar uma definição do fazer poético que se infere das ideias propostas pelo fenomenologista Maurice Merleau-Ponty: a arte é uma tentativa desesperada de se dizer o indizível (Merleau-Ponty, 1964, p. 319). A transgressão das propostas do romance de 30 que se observa em Vidas secas levam Luis Bueno à seguinte questão:

Não é curioso que este seja um livro em que, ao contrário do que acontece nos romances da seca típicos, os retirantes sejam focalizados durante o período em que não há secas? Na verdade, a seca aparece apenas no primeiro capítulo (e pressentida no último), fornecendo uma espécie de moldura para a narrativa, que acompanhará uma família de retirantes (ex e futuros retirantes, para ser mais preciso) exatamente quando está liberta da opressão natural mais forte, que é justamente a seca. (BUENO, 2008, p. 82).

Com relação a seu próprio "fazer-literário", Graciliano Ramos, em sua última entrevista, afirma: "Nunca pude sair de mim mesmo. Só posso escrever o que sou. E se os personagens se comportam de modos diferentes é porque não sou um só" (SENNA, 2012). De tal declaração pode-se inferir que o narrador é a 
instância mediadora que permite materializar um plurissignificante empilhamento palimpséstico de vozes, sobretudo no que se refere à impossibilidade do conhecimento unívoco sobre o universo em que vivemos. Pois bem, veja-se ainda, em correspondência de Graciliano Ramos, a indicação de que o mundo exterior é um pretexto para se propor um "escrutínio milimétrico do eu":

Escrevi um conto sobre a morte duma cachorra, um troço difícil como você vê: procurei adivinhar o que se passa na alma duma cachorra. Será que há mesmo alma em cachorro? Não me importo. $\mathrm{O}$ meu bicho morre desejando acordar num mundo cheio de preás. Exatamente o que todos nós desejamos. A diferença é que eu quero que eles apareçam antes do sono, e padre Zé Leite pretende que eles nos venham em sonhos, mas no fundo todos somos como a minha cachorra Baleia e esperamos preás. É a quarta história feita aqui na pensão. Nenhuma delas tem movimento, há indivíduos parados. Tento saber o que eles têm por dentro. Quando se trata de bípedes, nem por isso, embora certos bípedes sejam ocos; mas estudar o interior duma cachorra é realmente uma dificuldade quase tão grande como sondar o espírito dum literato alagoano. Referindo-me a animais de dois pés, jogo com as mãos deles, com os ouvidos, com os olhos. Agora é diferente. O mundo exterior revela-se a minha Baleia por intermédio do olfato, e eu sou um bicho de péssimo faro. (RAMOS, 1980, p.194-195).

Nessa obra em que a paisagem externa representa uma tentativa de tradução do indizível mundo interior, a mobilidade e a alternância do foco narrativo instalamse no discurso desse novo narrador e induzem o leitor a interpretar fatos e a assumir ou recusar múltiplos pontos de vista que emergem da descrição corrediça das ações e da fala ambígua das personagens. Por esse prisma, o narrador assume a mais humana condição, marcada pela ignorância quase absoluta sobre o universo e seus fatos, pela decorrente impossibilidade de julgar, pela incapacidade de anunciar eventos futuros. Personagens e leitor são induzidos a seguir por conta própria pelo intricado labirinto das múltiplas fontes enunciativas.

Nessa perspectiva, José Luis Fiorin (1996) discorre sobre a diferença fundamental entre os conceitos de "narrador" e de "observador" na prosa moderna: ao observador reserva-se o direito de saber, ver e ouvir; ao narrador cabe verbalizar, narrar e abster-se de observar circunstâncias e ações. As referidas funções alternam-se e por vezes se sobrepõem, em Vidas secas, no diapasão de diferentes focos narrativos, pois as técnicas narrativas de Graciliano induzem o leitor a se identificar ora com o narrador, ora com os personagens, ora com os 
narradores virtuais do extenso discurso hipertextual sobre o universo e a existência humana. Nesse caso, segundo Fiorin, trata-se de um processo de "focalização interna", terminologia cunhada por Jean Pouillon e Gérard Genette para qualificar o observador variável que se manifesta, de forma sub-reptícia, no discurso de um narrador que é o veículo intermediário da visão de outros personagens. Na vertente oposta, a "focalização externa" orienta apenas a descrição exterior das ações das personagens.

Em Vidas secas, tal como se manifestam no discurso palimpséstico do narrador, os conflitos internos e externos que estruturam a narrativa provocam um constante movimento de deslocamento do foco narrativo. Para Lígia Chiapinni Leite (1985), esse tipo de tratamento do foco narrativo corresponde a uma "onisciência seletiva múltipla", conforme nomenclatura proposta por Norman Friedman. Nesse caso, o narrador torna-se um mediador que semeia questionamentos e demonstra a complexidade do ato de exprimir em palavras o pensamento humano. Se, como quer Foucault, Dom Quixote lê o mundo para confirmar sua leitura dos livros, podese dizer que o leitor eficaz de Vidas secas expande sua consciência sobre a própria forma complexa de manifestar pensamentos e interpretar fatos que, em última instância, são múltiplos e ambíguos em razão da diversidade de possibilidades de atualizações por parte dos diferentes sujeitos que a ele se vinculam. Por tal razão, diz Chiapinni (1985), a "onisciência seletiva múltipla" induz a ocorrência do Discurso Indireto Livre, forma textual privilegiada de mediação entre narrador, autor, personagens e leitor.

\section{O Discurso Indireto Livre como forma de mediação indutiva}

O Discurso Indireto Livre (DIL) é um estilo narrativo no qual o discurso do narrador funde-se com o da personagem e, no mais das vezes, com os demais discursos que circulam nas margens do texto, inclusive o próprio pensamento do leitor - induzido pelos acontecimentos diegéticos. Utilizado desde o século XVII, o DIL traz em sua estrutura textual e conteudística marcas linguísticas que o distinguem daquelas que se encontram no discurso do narrador. Essas marcas representam interferências do discurso dos próprios personagens e podem ser expressadas pela variação de tempos verbais, pela ocorrência de dêiticos e de formas interrogativas, por características linguísticas e/ou psicológicas de personagens. Se o Discurso Direto e o Discurso Indireto solicitam a presença explícita de um 
verbum dicendi (dizer, contar, afirmar, relatar, pensar, acreditar etc.) que introduza uma fala direta ou reportada, o DIL implica o amálgama indissociável entre dois ou mais discursos que se sobrepõem, conduzindo a força expressiva do texto a uma múltipla possibilidade de leituras interpretativas.

O DIL dificulta a identificação dos portadores enunciativos do discurso inicial, ou mesmo da eventual condição de expressão de um mero pensamento ou ponto de vista reportado de forma sub-reptícia. Tal técnica narrativa permite aprofundar a ambiguidade do texto, acrescentar polissemia e ampliar a condição dialógica do texto, visto que as interações entre voz do narrador e voz dos personagens são mais complexas.

Mikhail Bakhtin (2009) analisa a condição dialógica do narrador flaubertiano e sustenta que, nesse autor, o DIL possibilita ao leitor reconhecer-se e introjetarse na entidade ficcional dos personagens, compartilhando, no tempo da leitura, de suas condições existenciais. Note-se que o narrador, ao mesmo tempo, revela traços inerentes dos personagens e conserva uma pretensa imparcialidade, de acordo com o foco narrativo induzido pelo DIL. Por outro lado, a interferência de um personagem na cena enunciativa provoca uma desestabilização no discurso do outro. O DIL, longe de transmitir uma impressão passiva produzida pela enunciação de outrem, exprime uma orientação ativa, que não se limita meramente a passagem da primeira a terceira pessoa, mas introduz, na enunciação citada. suas próprias entoações, que entram então em contato com as entoações da palavra reportada, interferindo nela.

De forma convergente, Igor Ávila (2012) retoma conceitos de Gothor-Mersch e sustenta que o DIL opera uma cisão das franjas sintáticas que delimitam os discursos do narrador e da personagem. Assim, a enunciação inscreve-se na plena mobilidade para dialogar com os elementos da narrativa e com o leitor, fato que resulta em ampliação das possibilidades expressivas do texto. Igor Ávila acrescenta ainda que, em leitura convergente, Michel Butor sustenta que o DIL é uma das principais estratégias para se obter a adesão do leitor às ideias manifestadas no discurso do narrador, por intermédio do emascaramento do portador da enunciação. Por esse viés, no processo de decifração das representações discursivas, as personagens constroem-se mutuamente por intermédio dos efeitos provocados pelo DIL:

Tal procedimento pode conciliar síntese e crítica, seja porque retoma elementos da fala de uma instância narrativa, incorporandoos ao discurso do narrador, seja porque efetua um deslocamento 
do discurso citado, que é apreendido fora do contexto e em outra situação enunciativa. Tal deslocamento produz um novo entendimento da personagem tomada por uma organização de discursos que lhe é própria, e portanto identificável como portadora de um repertório próprio, uma sintaxe, uma pragmática, enfim uma elocução particular. Estamos diante da expressão individualizada de cada personagem. Identificamos, então, duas camadas discursivas, sem que haja necessariamente uma ruptura sintática, uma fluidez que garante a leitura continua do enunciado em DIL, dessa forma, o resultado é um discurso duplo, mostrando dois pontos de vista diferentes, convivendo em um mesmo espaço enunciativo. (ÁVILA, 2012, p. 67).

No campo do discurso cinematográfico, Gilles Deleuze recorre a Pier Paolo Pasolini, cujas técnicas narrativas partem da ideia de que o DIL permite "la inmersión del autor en el ánimo de su personaje y, por lo tanto, la adopción, por parte del autor, no sólo de la psicología de su personaje, sino también de su lengua" (DELEUZE, 2005, p. 244). Como ilustração, pode-se dizer que tal é precisamente a característica mais expressiva na adaptação cinematográfica de Lavoura arcaica, por exemplo, cujas analepses, prolepses e dêiticos contribuem para que o espectador observe os elementos fílmicos como se participasse dos próprios acontecimentos diegéticos. Também nesse marco do cinema brasileiro, o DIL é uma forma de mediação indutiva, pois leva o leitor a abraçar diferentes pontos de vista e várias perspectivas interpretativas quanto ao fato sugerido pelas imagens (visuais, textuais e sonoras), quase sempre parciais, que constroem a trama. Com base nesses pressupostos, passemos à leitura das técnicas poéticas empregadas em Vidas secas.

\section{Discurso Indireto Livre em Vidas Secas: narrador, leitor e universo interior}

Partamos de um fato amplamente reconhecido pelos leitores de Graciliano: a estrutura de Vidas secas faz com que os capítulos possam ser lidos de forma independente e aleatória, como forma de representação da descontinuidade do percurso randômico e iterativo dos próprios personagens que fogem da seca cíclica e avassaladora, que tentam escapar da própria condição humana. Por outro lado, ilhados em arquipélago de silêncios mútuos, os capítulos autônomos parecem refletir a impossibilidade de encontros entre os seres humanos, tal como simboliza também a famosa cama de varas do par Vitória-Fabiano, cujo acasalamento é 
dificultado pela rigidez áspera do nó que se ergue em muralha entre ambos. Em razão do simbolismo desse nó que jamais se desata sobre (ou sob) enlaces de corpos, elegemos o capítulo IV, denominado "Sinhá Vitória", para propor uma leitura da função e dos efeitos do DIL nesse texto que se revela uma ilha no sertão literário nacional. No capítulo em tela, o narrador inicia sua narração apresentando, de forma vaga e imprecisa, o espaço em que Sinhá Vitória desenvolve um certo número de ações:

ACOCORADA junto às pedras que serviam de trempe, a saia de ramagens entalada entre as coxas, Sinhá Vitoria soprava o fogo. Uma nuvem de cinza voou dos tições e cobriu-lhe a cara, a fumaça inundou-lhe os olhos, o rosário de contas brancas e azuis desprendeu-se do cabeção e bateu na panela. Sinhá Vitória limpou as lágrimas com as costas das mãos, encarquilhou as pálpebras, meteu o rosário no seio e continuou a soprar com vontade, enchendo muito as bochechas. (RAMOS, 1979, p. 21).

Para apresentar algumas ações reciprocamente desconexas realizadas ou sofridas por Sinhá Vitória, o narrador serve-se de certos recursos linguísticos que rapidamente aproximam o leitor da história: por exemplo, o artigo definido em "a saia", "o fogo", "o rosário" tem função catafórica, induzindo o leitor a pressupor o seu próprio conhecimento prévio da existência desses elementos que compõem o espaço físico em que transcorrem as ações. O leitor é levado a imergir no espaço textual, na própria trama, como se estivesse ali antes mesmo que as ações tivessem começo. Cabe sublinhar que, à diferença da estética de matriz realista, em Graciliano a alusão vaga e imprecisa ocupa o lugar da descrição impessoal e minuciosa. Ao fechar o livro, o leitor pouco saberia dizer sobre as características físicas dos ambientes e personagens, mas poderia tecer longas considerações sobre os traços psicológicos dos protagonistas. As imagens insólitas e imprecisas contribuem para lançar o leitor numa atmosfera de sonho que, ao fim e ao cabo, revela-se o pesadelo da existência.

De forma complementar no âmbito do DIL, outro recurso linguístico é a sobreposição de registros de linguagem que representam o universo do leitor e o universo das personagens. Por exemplo, ao dizer que Sinhá Vitória está "acocorada", sua saia está "entalada", "o rosário desprendeu-se do cabeção" e que a personagem "meteu o rosário no seio", o narrador serve-se do registro regional e popular, que se mescla de maneira segura com a norma culta da língua que se vê 
em "junto às" e "desprendeu-se": o narrador, tal como sucede no DIL, amalgama de forma indissociável as falas e formas discursivas de diferentes instâncias narrativas, do leitor às personagens, do narrador ao conjunto hipertextual dos discursos possíveis. O leitor é induzido a refletir sobre a origem de cada um dos fragmentos discursivos que se manifestam nas palavras do narrador. Curiosamente, logo a seguir, o leitor se depara com outra descrição, agora da cachorra Baleia:

Labaredas lamberam as achas de angico, esmoreceram, tornaram a levantar-se e espalharam-se entre as pedras. Sinhá Vitória aprumou o espinhaço e agitou o abano. Uma chuva de faíscas mergulhou num banho luminoso a cachorra Baleia, que se enroscava no calor e cochilava embalada pelas emanações da comida. Sentindo a deslocação do ar e a crepitação dos gravetos, Baleia despertou, retirou-se prudentemente, receosa de sapecar o pelo, e ficou observando maravilhada as estrelinhas vermelhas que se apagavam antes de tocar o chão. Aprovou com um movimento de cauda aquele fenômeno e desejou expressar a sua admiração à dona. Chegou-se a ela em saltos curtos, ofegando, ergueu-se nas pernas traseiras, imitando gente. Mas Sinhá Vitória não queria saber de elogios. Arreda! Deu um pontapé na cachorra, que se afastou humilhada e com sentimentos revolucionários. (RAMOS, 1979, p. 21).

Nesse excerto, observa-se a antropomorfização da cachorra Baleia que "cochilava" e "despertou, retirou-se prudentemente, receosa de sapecar o pelo, e ficou observando maravilhada as estrelinhas vermelhas", além de, nas palavras do narrador, ter a capacidade humana de "aprovar aquele fenômeno", "desejar expressar sua admiração", "imitar gente" e ter "sentimentos revolucionários". Observe-se, desde já, que o dêitico catafórico "aquele fenômeno" corresponde a um dos recursos expressivos do DIL, pois, tal como os artigos definidos explicados acima, induz o leitor a assumir sua presença testemunhal no local em que transcorrem as ações. (cf. ALVAREZ; LOPONDO, 2012).

Por outro lado, os trechos acima constroem-se de maneira a reafirmar o processo de animalização de Sinhá Vitória, que "acocorada" (como um animal), tem "espinhaço" e "cara" de animal. Essa troca de posições decorre das condições a que os seres humanos são submetidos no espaço simbólico narrativo: isolamento, fome, desabrigo, condições climáticas desfavoráveis, lida contínua com animais, sistema opressivo, miséria material, intelectual e linguística. Em tal contexto, as personagens utilizam uma linguagem limitada a grunhidos e interjeições quase sempre monossilábicos, ou que se prolongam em sílabas 
onomatopaicas que mimetizam sons produzidos por animais, impossibilitando a comunicação, como no rosnar que se ouve em "arreda!". O narrador alude a tal incomunicabilidade e incapacidade de compreensão do universo por parte dos personagens, trazendo, subentendidos em sua narrativa, os pensamentos e sensações de Sinhá Vitória e Fabiano, como se vê também neste trecho:

Sinhá Vitória tinha amanhecido nos seus azeites. Fora de propósito, dissera ao marido umas inconveniências a respeito da cama de varas. Fabiano, que não esperava semelhante desatino, apenas grunhira: - "Hum! hum!" E amunhecara, porque realmente mulher é bicho difícil de entender, deitara-se na rede e pegara no sono. Sinhá Vitória andara para cima e para baixo, procurando em que desabafar. Como achasse tudo em ordem, queixara-se da vida. E agora vingava-se em Baleia, dando-lhe um pontapé. (RAMOS, 1979, p. 21).

Nos excertos "Sinhá Vitória tinha amanhecido nos seus azeites" e "porque realmente mulher é bicho difícil de entender", observa-se a clara emergência do DIL para induzir o leitor a buscar descobrir se essas ideias correspondem ao discurso apenas do narrador, ou se refletem a fala ou o pensamento dos personagens, ou mesmo o discurso corrente que pode espelhar a própria ideologia do leitor ou da cultura de que emerge o texto ("mulher é bicho difícil de entender"). O efeito do DIL é ampliado com o uso de expressões populares ou regionais mescladas à fala regida pela norma culta da língua portuguesa (com uso do tempo verbal mais-que-perfeito, sobretudo na forma simples, por exemplo: "dissera", "andara", "queixara-se" etc.). Por meio de tais recursos linguísticos, o leitor é novamente induzido a projetar-se no texto, no universo e no discurso dos personagens, confundindo-se com eles a ponto de já não poder identificar os segmentos de discurso que lhe são próprios e os que lhe são alheios.

O tipo de focalização utilizada em Vidas secas permite uma mais profunda representação da complexidade psicológica das personagens, conduzindo o leitor pelos meandros de uma incômoda prospecção dos abismos da alma humana. No trecho a seguir, uma atmosfera de pesadelo constrói-se por meio de um vocabulário vago e impreciso, de imagens insólitas, do emprego de dêiticos anafóricos, de um léxico resultante da confluência de múltiplos registros de linguagem (popular, culto, erudito, regional, urbano, rural, neológico, arcaico, infantil, religioso, técnico, escatológico etc.); e, por evidente, pelo emprego dos tempos verbais característicos do DIL (sobretudo o pretérito imperfeito do 
indicativo, com sua função de embreagem de tempos e espaços imaginários), condições que induzem o leitor a instalar-se na mente das personagens:

Tudo ali era estável, seguro. O sono de Fabiano, o fogo que estalava, o toque dos chocalhos, até o zumbido das moscas davam-lhe sensação de firmeza e repouso. Tinha de passar a vida inteira dormindo em varas? Bem no meio do catre havia um nó, um calombo grosso na madeira. E ela se encolhia num canto, o marido no outro, não podiam estirar-se no centro. A princípio não se incomodara. Bamba, moída de trabalhos, deitar-se-ia em pregos. Viera, porém, um começo de prosperidade. Comiam, engordavam. Não possuíam nada: se retirassem, levariam a roupa, a espingarda, o baú de folha e troços miúdos. Mas iam vivendo, na graça de Deus, o patrão confiava neles - e eram quase felizes. Só faltava uma cama. Era o que aperreava Sinhá Vitória. Como já não se estafava em serviços pesados, gastava um pedaço da noite parafusando. E o costume de encafuar-se ao escurecer não estava certo, que ninguém é galinha. (RAMOS, 1979, p. 24).

O empilhamento palimpséstico de discursos e ideias alheias que se materializa no discurso do narrador implica múltiplas possibilidades interpretativas para a passagem em tela. Para o leitor, Sinhá Vitória pode estar sonhando, devaneando sobre sua vida, interrogando-se sobre sua condição; o narrador pode estar observando e sondando os conflitos interiores da personagem; mas, em qualquer das hipóteses, o leitor é induzido a inscrever-se no circuito dos pensamentos que se manifestam nesses fragmentos discursivos. Nesse caso, à figura do narrador agregam-se as ferramentas do DIL como instrumento de mediação indutiva, anulando-se, em maior ou menor grau, os espaços ontológicos que separam personagens e leitor. Nesse processo de identificação induzida pelos recursos estilísticos, a solidão humana reflete-se no próprio ambiente em que transcorre a ação: o leitor atento poderá observar, na superfície do texto, que seres e objetos são singularizados por meio do emprego recorrente de unidades lexicais no singular: artigos definidos e indefinidos; pronomes pessoais, possessivos ou demonstrativos; substantivos etc.

Ao mesmo tempo, o narrador acaba por dissolver-se em seu próprio discurso, em razão da condição corrediça das instâncias narrativas. Por meio do DIL, a fala do narrador dissolve-se no curso de uma mudança de registro de linguagem, em que a norma culta se mescla com a linguagem popular: "A princípio não se incomodara. Bamba, moída de trabalhos, deitar-se-ia em pregos". A mesóclise de "deitar-se- 
ia" é emblemática: o registro, claro está, corresponde às formas discursivas do leitor, que maneja a norma culta da língua escrita (ainda que a mesóclise esteja em desuso, nos dias de hoje, na variante brasileira da língua portuguesa); contudo, a expressão corresponde também ao pensamento, transposto para a norma culta por meio do futuro do pretérito do indicativo, da própria personagem de Sinhá Vitória que, no discurso direto, diria "estou moída, me deitava até em pregos"; ou, no discurso indireto, teríamos "Sinhá Vitória pensou que estava tão bamba que deitaria até em pregos". Graciliano serve-se dos tempos verbais em sua função poeticamente expressiva, uma vez que o pretérito imperfeito e o futuro do pretérito (condicional) do indicativo funcionam como embrayeurs e lançam o leitor no espaço das cogitações e da imaginação, espaço que se compartilha, em situação de leitura, com a própria imaginação (fictícia) dos personagens. Tal é, aliás, a função desses tempos verbais segundo a análise de Gianni Rodari (1979), anteriormente intuída por Graciliano, como se vê já na epígrafe do presente estudo, trecho revelador extraído de carta dirigida a Ricardo Ramos (1987, p. 13): "O importante é escrever duas páginas no condicional sem que ninguém perceba".

Assim, no conjunto das passagens de Vidas secas aqui analisadas, observase que o narrador é marcado pela "onisciência seletiva múltipla" de que trata Lígia Chiappini Leite (1985), inclusive no que se refere à autoconsciência da incompletude semântica do pensamento humano, ainda que a obra possa ser lida, em princípio, na esteira realista da Geração de 30. O narrador, encastrado como pedra corrediça na poenta trama, torna-se, por meio do DIL, o mediador essencial da dúvida ontológica, colocando em cheque a possibilidade de outorgar um sentido - tanto semântico quanto dêitico -, uma direção (indecifrável), um apontamento (vazio) para uma narrativa que expressa o vácuo da existência humana. $\mathrm{O}$ drama social transborda sobre o drama existencial, o local deságua sobre o universal, por meio de procedimentos estilísticos e de empilhamentos de vozes palimpsésticas que fazem de Vidas secas uma obra ímpar no conjunto da produção literária da Geração de 30.

\section{Considerações transitórias finais}

Nas páginas de Vidas secas, o leitor tem acesso a uma pequena parcela da odisseia de retirantes nordestinos nos sendeiros ressequidos do agreste do sertão, em franca convergência com a estética característica da Geração de 30. Por outro 
lado, o romance de Graciliano Ramos contribui para transformar as categorias de expressão narrativa, enquanto seu narrador ocupa a função de mediador entre leitor e personagem, entre imaginário e realidade empírica, entre o cotidiano e o universo atemporal. Em tal contexto, o foco narrativo corrediço contribui para delinear aproximações e distanciamentos no que tange aos conflitos interiores e exteriores dos personagens, trazendo para a trama múltiplas vozes que ampliam o leque de possibilidades interpretativas. Para além do neorrealismo de seus coetâneos, Ramos entrega-se à prática do DIL antropofágico e induz o leitor a um processo de transição permanente entre diferentes pontos de vista sobre si próprio e sobre a condição humana, assim como à árdua tarefa de construir sentidos para o texto literário e para sua própria existência, irremediavelmente presa nos impenetráveis abismos da alma humana, tal como ilustram os inenarráveis personagens cruamente realistas, as circunstâncias pretextuais e os recursos linguísticos articulados nas páginas de Vidas secas.

\title{
Médiation discursive et la Génération de 30: Graciliano Ramos et l'entassement palimpsestique de voix et de recours stylistiques
}

\begin{abstract}
Résumé
Vidas secas (1938), de Graciliano Ramos, adopte les prescriptions poétiques du Roman de 30 et prend comme prétexte le drame social et existentiel des rescapés de successifs cycles de sécheresse, l'une des caractéristiques du Sertão. L'auteur, par le moyen de fort expressifs recours stylistiques, conduit le lecteur vers la prospection de l'espace qui se trouve entre la conscience (fictive) des personnages et le vaste hypertexte dans lequel vient s'exprimer le drame de l'humaine condition. Dans un tel contexte, l'objectif de la présnte étude est celui d'analyser les techniques d'écriture mises en œuvre dans les pages de Vidas secas, notamment en ce qui concerne le Diecours Indirect Libre, dans le but de dévoiler les traits poétiques et stylistiques qui permettent l'expression de certaines formes de médiation discursive, ainsi que l'émergence de nombreuses possibilites interprétatives. Par le biais d'un discours qui se développe sous des multiples registres de langage, le narrateur se conçoit comme le médiateur de fort imbriquées cartographies de l'existence : les différentes instances narratives et sources d'énociation émergent d'un efficace entassement palimpsestique de couches verbales d'origines les plus diverses.
\end{abstract}

Mots-clefs: Vidas secas. Condition humaine. Génération de 1930. Stylistique. Médiation discursive. 


\section{Referências}

ALVAREZ, Aurora; LOPONDO, Lílian. O discurso da exclusão: um estudo da dêixis no texto literário. Desenredo. v. 8, n. 1. jan./jun. 2012, p. 100-114. Disponível em $<$ http://www.upf.br/seer/index.php/rd/article/view/2641>. Acesso em 05, março, 2015.

ÁVILA, Igor M. Discurso indireto livre em Madame Bovary: o despontar da forma. O Discurso indireto livre em Madame Bovary de Gustave Flaubert. O despontar da forma. Dissertação (Mestrado em Letras Modernas). São Paulo: USP, 2012. Disponível em: <http://www.teses.usp.br/teses/disponiveis/8/8146/ tde-14092012-105825/publico/2012_IgorMilenkovichAvila.pdf $>$. Acesso em 5 março, 2015.

BAKHTIN, Mikhail. Marxismo e filosofia da linguagem. Tradução de Michel Lahund e Iara Frateschi Vieira. São Paulo: HUCITEC, 2009.

BUENO, Luís. Antonio Cândido leitor de Graciliano Ramos. Revista Letras. n. 74. Curitiba: Editora UFPR, n. 74, p. 71-85, 2008. Disponível em: <http://ojs.c3sl. ufpr.br/ojs2/index.php/letras/article/view/10944>. Acesso em: 5 março, 2015.

CANDIDO, Antonio. Ficção e confissão: ensaios sobre Graciliano Ramos. Rio de Janeiro: Editora 34, 1992.

CARVALHO, Luiz Fernando (direção). Lavoura arcaica. Rio de Janeiro: Riofilme, 2001. [DVD]

CERQUIGLINI, Bernard. Le style indirect libre et la modernité. Langages. v. 19, n. 73. Março 1984, p. 7-16. Disponível em: <http://www.persee.fr/web/revues/ home/prescript/article/lgge_0458-726x_1984_num_19_73_1162>. Acesso em: 12 março, 2015.

CHARTIER, Pierre. Introduction aux grandes théories du roman. Paris: Bordas, 1995.

DELEUZE, Gilles. La imagen-movimiento. Estudios sobre cine. Buenos Aires: Paidós, 2005.

FIORIN, José Luís. As astúcias da enunciação. São Paulo: Ática, 1996.

LEITE, Lígia Chiappini Moraes. O foco narrativo. São Paulo: Ática, 1985.

MERLEAU-PONTY, Maurice. Le visible et l'invisible. Paris: Gallimard, 1964.

RAMOS, Graciliano. Vidas secas. São Paulo, Record, 1938 - 1979.

RAMOS, Graciliano. Cartas. Rio de Janeiro: Record, 1980. 
RAMOS, Ricardo. Lembrança de Graciliano. In: GARBUGLIO, José Carlos; BOSI, Alfredo; FACIOLI, Valentim. Graciliano Ramos. São Paulo: Ática, 1987. REUTER, Yves. Introdução à análise do romance. São Paulo: Martins Fontes, 1996.

RODARI, Gianni. Grammaire de l'imagination. Paris: Messidor, 1979.

SENNA, Homero. A última entrevista de Graciliano Ramos (1948). Jornal Opção. n. 1944. 7-13/out/2012. Disponível em: <http://www.jornalopcao.com. br/posts/opcao-cultural/a-ultima-entrevista-de-graciliano-ramos $>$. Acesso em: 15 março 2015.

Recebido em 22/04/2016

Aceito em 05/09/2016 